\title{
Advances in the treatment of children with phonological disorders
}

\author{
Marizete Ilha Ceron', Karina Carlesso Pagliarin², Márcia Keske-Soares³. \\ 1) Speech-Language Pathologist; Doctoral Student of Human Communication Disorders at Universidade Federal de Santa Maria (UFSM), Santa Maria / RS, Brazil; Master \\ in Human Communication Disorders at UFSM. \\ 2) Speech-Language Pathologist; Doctoral Student of Psychology with an emphasis on Human Cognition at Pontifícia Universidade Católica do Rio Grande do Sul (PUCRS), \\ Porto Alegre / RS, Brazil. \\ 3) Speech-Language Pathologist; Doctor of Applied Linguistics at PUCRS. Professor associated with the Speech-Language Course and the Postgraduate Program in Human \\ Communication Disorders at UFSM. \\ Institution: This study was carried out as part of the Graduate Program in Human Communication Disorders, UFSM, Santa Maria / RS, Brazil, with scholarship \\ support from the Coordenação de Aperfeiçoamento de Pessoal de Nível Superior (CAPES) \\ Santa Maria/RS - Brazil. \\ Mailing address: Marizete Ilha Ceron Rua Bentevi, 215, Bairro JK - Santa Maria / RS - Brazil - Zip Code: 97035-130 - E-mail: marizeteceron@ hotmail.com \\ Article received on January 10th, 2013. Article accepted on March 10th, 2013
}

\section{SUMMARY}

Introduction: Treatment of phonological disorders considering extra-linguistic and linguistic variables are important to ensure that the alteration is resolved promptly and in the best manner as possible.

Aim: To analyze therapeutic advances (phonetic inventory, phonological system, and distinctive features) in children with phonological disorders by considering the therapeutic approach used, the severity of the phonological disorder, age, and the number of therapeutic sessions.

Methods: We conducted a case series study of 94 children aged 3 years, 9 months through 8 years, 5 months. The children were divided into groups based on the therapeutic approach used (Modified Cycles, Maximal Oppositions, ABAB-Withdrawal, and Multiple Probes), the severity of their phonological disorder, age, and the number of therapy sessions with each individual. Phonetic inventory, the phonological system, and the number of altered distinctive features were analyzed.

Results: The greater the number of therapy sessions, the greater the number of sounds acquired. The number of sounds present in the phonetic inventory and phonological system increased and the severity of the phonological disorder decreased with all of the therapeutic approaches studied. There was also a reduction in the incidence of altered distinctive features.

Conclusion: There was a favorable evolution in phonetic inventory and phonological system acquisitions as well as a reduction in the number of altered distinctive features for all 3 therapeutic models regardless of the severity of the phonological disorder, age, or number of sessions.

Keywords: Articulation Disorders; Speech Disorders; Speech, Language and Hearing Sciences; Speech Therapy.

\section{INTRODUCTION}

Phonological disorders in children have been the subject of several studies aiming to identify the optimal remedial treatment (1-8). Nevertheless, before any phonological therapy can begin, the speech therapist has to carry out a wide ranging and complete phonological evaluation in order to exclude alterations (motor, neurological) that are not correlated with any phonological disorder $(5,6,8)$. In addition, it is important to have knowledge about normal phonological acquisition, that is, information regarding the phonemes that are expected to be produced correctly by children at each age and how these are organized contrastively in the language. Knowledge of normal acquisition patterns enables the therapist to evaluate evidence of abnormal acquisition and determine whether the child has a phonological disorder.

This phonological evaluation also provides the therapist with the following information: details relating to the organization of phonemes in the child's speech, that is, which sounds are present or absent from the phonological inventory; information on which phonemes have been acquired by the phonological system (9); an indication as to whether the sounds that are absent from the phonological inventory are stimulable (10); identification of altered distinctive features; and an understanding of the severity of the phonological disorder. All of these factors will assist in the selection of a suitable treatment model and of the most adequate sound targets for each child (11). This in turn requires the therapist to be informed about existing models and the principles underlying their approach in order for the therapy to be completed both quickly and effectively.

Several such models have been described in the literature. In this study, the following models were evaluated: the ABAB - Withdrawal and Multiple Probes Model (12); the Maximal Oppositions Model (13); and the Modified Cycles Model (14). These models differ from one another in the number of target sounds selected for therapy, the number of sessions, and the underlying principles behind the 
treatment (based on phonological processes and distinctive features).

The ABAB - Withdrawal and Multiple Probes (12) model is based on the fact that in order to teach a more complex sound, the acquisition of less complex sounds with no direct intervention is required. The Maximal Oppositions model (13) operates on the principle of contrasting words that differ in only one phoneme, and these phonemes contrast in few or several distinctive features. Distinctive features are components that characterize a phoneme it is crucial to distinguish mark between two phonemes. Example of distinctive oppositions in Portuguese are the phonemes / $\mathrm{f} /$ and / $\mathrm{v} /$ differing only in voice feature as in the word pairs "faca" $\mathrm{x}$ "vaca". Finally, the Modified Cycles model (14) is based upon the elimination of phonological processes that affect the child's speech by increasing awareness of the characteristics of the target sounds in that phonological process.

These approaches have important clinical implications. A number of studies have suggested that these models are capable of improving the speech of children with phonological disorders of differing severities $(1-3,5-7)$.

In this context, it is necessary to analyze the extralinguistic and linguistic variables associated with the treatment of phonological disorders to ensure that the alteration is resolved promptly and in the best manner possible. Therefore, this study aimed to analyze the therapeutic processes (phonetic inventory, phonological system, and distinctive features) in children with phonological disorders, considering the therapy model used, the severity of the phonological disorder, the age of the child, and the number of therapy sessions.

\section{Methods}

\section{Participants}

All participants were Brazilian and native Portuguese speakers. The initial sample consisted of 130 children with phonological disorders who were recruited from an existing database from a research project that was approved by the Research Ethics Committee of a higher-level institution (number 046/02). After clarification of the objectives of the study, all parents signed a consent form authorizing the participation of their child in the research project as well as the publication of the study results.

The following inclusion criteria were used: (a) phonological assessment performed before and after treatment; (b) different severities of phonological disorders; and (c) treatment with the Modified Cycles, Maximal Oppositions, or ABAB-Withdrawal and Multiple Probes models. After analysis of the inclusion criteria, 94 children aged 3 years, 9 months through 8 years, 5 months were selected. There were 32 girls and 62 boys.

\section{Instruments and procedures}

All children underwent the following evaluations: comprehensive and expressive language, buccofacial assessment, auditory discrimination test, articulatory examination (word repetition), and phonological evaluation. The results of these evaluations were within the normal ranges for each age group, except for the phonological evaluation. The children also underwent complementary evaluations (audiological, otorhinolaryngological, and neurological), with the aim of excluding any organic or functional injury.

The Phonology Assessment (Phonological Assessment of the Child- PAC) (15) data were used to examine phonological ability by identifying and classifying error patterns in a child's speech. The assessment consisted of naming and describing 6 images: bedroom, zoo, circus, bathroom, kitchen, and room. These allow elicitation of all consonants in the syllable-initial and final positions and make it possible to ascertain the child's phonetic inventory and phonological system.

A sound was considered to have been acquired and become a part of the phonetic inventory when it occurred twice or more in the child's speech. In order to ascertain the phonological system, we considered a phoneme to be acquired when it was produced correctly 80\%-100\% of the time; partially acquired when it was produced correctly $40 \%-79 \%$ of the time; and unacquired when it was produced correctly 0\%-39\% of the time (16).

To measure the degree of severity of speech error, The Percentage of Consonants Correct-Revised (PCC-R) (17) was calculated from the phonology data, which were identified and classified as follows: mild disorder (86\%100\%); mild-moderate disorder (66\%-85\%); moderate-severe disorder (51\%-65\%); and severe disorder (<50\%). In this study, only 6 children were classified as having a severe speech disorder, and so they were all included in the moderate-severe group to facilitate the statistical analysis.

\section{Intervention}

All 94 children received phonological treatments suited to their phonological systems. The approaches used 
were as follows: ABAB-Withdrawal and Multiple Probes, Maximal Oppositions, and Modified Cycles. The groups are characterized in Figure 1, which shows the therapeutic model, speech severity, and sex.

The ABAB-Withdrawal and Multiple Probes (12) model is based on the fact that teaching a more complex sound implies the acquisition of a less complex sound without any direct intervention. In this approach, just one target sound is selected during each cycle ( 9 sessions). At the end of the treatment cycle, 5 more sessions are performed, including a period of withdrawal, which consists of an interval without direct treatment for the target sound. In these sessions, spontaneous speech and image-naming data are collected and the clinician observes the acquired sounds (target and non-target sounds) in the child's phonological system.

The Maximal Oppositions Approach (13) highlights contrasts using pairs of words that differ by a single phoneme. The differences in the features of the phonemes are the focus of treatment. Five pairs of words are selected to be worked on over approximately 5 sessions (e.g., sadmad, sat-mat). In this model, the child has to distinguish between phonemes by imitation and spontaneous production. At the imitation level, the child repeats the sound modeled by the clinician. At the productionindependent appointment level, the child has to produce the target sound represented pictorially in the same set of words used at the imitation level, but without the adult modeling the sound. In production-level pairs, the phonemes are presented as pairs of words that are also represented pictorially. The child must get at least $50 \%$ of these pairs correct to move to the sentences level.

The Modified Cycles Model (14) involves the suppression of phonological processes in the child's speech and the program has a duration of 3 weeks. Each week, 1 phonological process is worked on, with a focus on 1 or 2 target sounds in each process. By the end of each session, the pictures worked on are reviewed, and if the child produces $20 \%$ or more of the target words correctly, then he/she moves on to another sound during the following session. However, if the participant produces $<20 \%$ of the target words correctly, the same target words are worked on in the following session.

In the present study, the children were divided into age groups (the average age was 1 year, 6 months): F1 3 years, 9 months through 5 years, 3 months; $\mathrm{F} 2-5$ years, 4 months through 6 years, 10 months; and F3 - 6 years, 11 months through 8 years, 5 months. They were also divided into groups based on the number of treatment sessions: NS1 - 5-18 sessions; NS2 - 19-36 sessions; and NS3 - more than 37 sessions.

\section{Data Analysis}

The parameters analyzed included the number of acquired sounds in the phonological system, the phonetic inventory, and altered distinctive features after treatment with respect to the therapeutic model, speech severity, number of sessions, and age. One-way ANOVA and a Bonferroni post-hoc test were used for the analyses. An ANCOVA was performed for age because of a betweengroup difference. Data were analyzed with SPSS version 17.0 for Windows, with significance set at $\mathrm{p} \leq 0.05$.

The analyses of the distinctive features were performed by verifying the substitutions in a contrastive analysis. In order to characterize the altered distinctive features from these substitutions, we used the geometry of features of the consonants in English (18). All replacements were considered in more than $10 \%$ of the possibilities.

\section{RESULTS}

When the ABAB - Withdrawal and Multiple Probes, Maximal Oppositions, and Modified Cycles models were compared with regard to the severity of phonological

Figure I. Distribution of participants according to therapeutic model, speech severity, and sex.

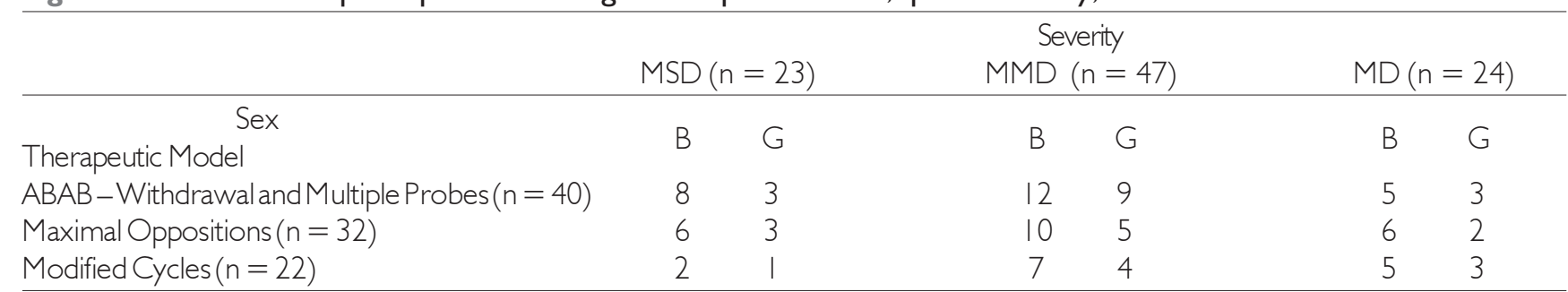

Subtitle: $\mathrm{n}=$ number of subjects; $\mathrm{B}=$ boy, $\mathrm{G}=$ girl; $\mathrm{MSD}=$ moderate-severe disorder; $\mathrm{MMD}=$ mild-moderate disorder; $\mathrm{MD}=$ mild disorder. 
disorder and the number of sessions, no differences were observed. The average age was also similar among the models: the major difference in age was observed between the ABAB - Withdrawal and Multiple Probes and the Modified Cycles models (Table 1).

The averages and standard deviations of the differentials obtained during the evaluations of the phonetic inventory, phonological system, and altered distinctive features before and after treatment, and the comparisons of the therapeutic models, the severity of the phonological disorders, age, and the number of sessions can be found in Table 2.

Regarding the therapeutic models, no differences in the phonetic inventory and the phonological system were observed among the models analyzed since the quantity of absent sounds was similar among the participants in each of the 3 models. Nevertheless, a difference concerning the distinctive features was found, mainly between the ABAB - Withdrawal and Multiple Probes Model and the other models.

When the severity of the phonological disorders was compared, the data showed that the severity was significantly reduced as the number of absent phonemes in the phonetic inventory and phonological system was reduced. Regarding distinctive features, a significant reduction in the number of altered features was also observed as the severity of the disorder was reduced.

With regard to age, the younger the child, the greater the number of novel sounds in the phonetic inventory and the greater the number of acquired phonemes in the phonological system, and so also the lower the number of altered distinctive features.

Regarding the number of sessions, there was a difference among the variables analyzed because the higher the number of sessions, the more sounds acquired and the lower the number of altered features present.

\section{DISCUSSION}

There were no statistically significant differences in the severity of the phonological disorders and the number of therapy sessions among the models compared (ABAB Withdrawal and Multiple Probes, Maximal Oppositions and Modified Cycles) (Table 1). This shows that all 3 approaches were effective in treating children with phonological disorders. Besides, children with phonological disorders of the same level of severity had the same number of therapy sessions. The age of the children in each model differed slightly, but this did not affect the results for the development of the phonetic inventory and phonological system (Table $2)$.

Even though there is evidence suggesting that a variety of approaches are effective for children with phonological disorders, little is known about the most efficient approach in general or the most efficient approach for a particular group of children (19). Nonetheless, it is believed that comparing the therapeutic models assists the professional in selecting the most efficient therapeutic approach $(12,20)$.

According to a study (11) involving English speakers, particular models can be more efficient for specific severities of phonological disorders than others. Nonetheless, these studies are inconclusive and more studies with a greater number of subjects are needed in order to support these findings. Our study used a large sample but supports the findings from these previous studies. Thus, it is not possible to say which model is more effective among the 3 models compared because all led to the acquisition of new phonemes.

Table I. Comparison of the therapeuticmodels based on the severity of the phonological disorder, age, and the number of sessions.

\begin{tabular}{|c|c|c|c|}
\hline & $\begin{array}{l}\text { Severity } \\
A(s d)\end{array}$ & $\begin{array}{l}\text { Age } \\
A(s d)\end{array}$ & $\begin{array}{c}\text { Number of sessions } \\
\qquad \mathrm{A}(\mathrm{sd})\end{array}$ \\
\hline \multicolumn{4}{|l|}{ Model } \\
\hline ABAB - Withdrawal and Multiple Probes $(n=40)$ & $72,96(\mid 4,47)$ & $67.12(11.22)$ & $24.08(10.27)$ \\
\hline Maximal Oppositions $(n=32)$ & $74,7 \mid(\mid 5,54)$ & $68.69(12.70)$ & $26.19(17.7 \mid)$ \\
\hline Modified Cycles $(n=22)$ & $81,8 \mid(\mid 1,55)$ & $75.78(12.83)$ & $24.14(15.65)$ \\
\hline p-value & 0,64 & 0,029 & 0,802 \\
\hline Posthoc & & ABAB $\times$ Cycles* & \\
\hline
\end{tabular}

* Statistically significant correlation (p£0,05) - Test One-way ANOVA and Post-Hoc Bonferroni

Subtitle: $\mathrm{n}=$ number of subjects; $\mathrm{A}$ = average; $\mathrm{sd}$ = standard deviation 
Table 2. Comparison of the therapeutic models based on the severity of the phonological disorder, age, and thenumber of sessions with respect to differentials in the phonetic inventory, phonological system, and altered distinctive features.

\begin{tabular}{|c|c|c|c|}
\hline & $\begin{array}{l}\text { Phonetic Inventory } \\
\qquad \mathrm{A}(\mathrm{sd})\end{array}$ & $\begin{array}{l}\text { Phonological Sistem } \\
\text { A (sd) }\end{array}$ & $\begin{array}{c}\text { Distinctive Features } \\
\mathrm{A}(\mathrm{sd})\end{array}$ \\
\hline $\begin{array}{l}\text { Model } \\
\text { ABAB-Withdrawal and Multiple Probes }(n=40) \\
\text { Maximal Oppositions }(n=32) \\
\text { Modified Cycles }(n=22) \\
\text { p-value } \\
\text { Post-hoc }\end{array}$ & $\begin{array}{c}2.08(2.04) \\
2.16(2.4 I) \\
1.45(2.20) \\
.892\end{array}$ & $\begin{array}{c}4.05(2.80) \\
3.16(2.90) \\
2.59(2.74) \\
.275\end{array}$ & $\begin{array}{c}9.18(7.28) \\
4.88(5.44) \\
4.50(4.78) \\
.011 \\
\text { ABAB } \times \text { Maximal Oppositions *** } \\
\text { ABAB } \times \text { Cycles*** }\end{array}$ \\
\hline $\begin{array}{l}\text { Severity } \\
\operatorname{MSD}(n=24) \\
\operatorname{MMD}(n=47) \\
\operatorname{MD}(n=23) \\
\text { p-value } \\
\text { Posthoc }\end{array}$ & $\begin{array}{c}4.25(1.96) \\
1.58(1.66) \\
.44(1.47) \\
.000 \\
M S D \times D M M * * \\
M S D \times D M^{*} * * \\
D M M \times D M^{*}\end{array}$ & $\begin{array}{c}5.33(3.37) \\
3.31(2.60) \\
1.72(1.21) \\
0.000 \\
M S D \times D M M^{*} \\
D M M \times D M^{*} \\
M S D \times M^{*} *\end{array}$ & $\begin{array}{c}\text { I I.88 (8.03) } \\
5.93(5.08) \\
2.80(3.27) \\
.000 \\
\text { MSD } \times \text { DMM*** } \\
\text { MSD } \times \text { DM } * \text { *** }\end{array}$ \\
\hline $\begin{array}{l}\text { Age Ranges (month) } \\
\text { FI }(n=3 I) \\
\text { F2 }(n=46) \\
\text { F3 }(n=17) \\
\text { p-value } \\
\text { Posthoc }\end{array}$ & $\begin{array}{l}3.13(2.29) \\
1.65(2,11) \\
.65(1.06) \\
.000 \\
\mathrm{FI} \times \mathrm{F} 2 * * \\
\mathrm{FI} \times \mathrm{F} 3 *\end{array}$ & $\begin{array}{c}4.16(2.92) \\
3.35(2.58) \\
2.18(3.11) \\
.065\end{array}$ & $\begin{array}{l}8.52(6.54) \\
6.59(6.59) \\
3.24(4.85) \\
.025 \\
\mathrm{FI} \times \mathrm{F}^{*} *\end{array}$ \\
\hline $\begin{array}{l}\text { Number of sessions } \\
\text { NSI }(n=39) \\
\text { NS2 }(n=38) \\
\text { NS3 }(n=17) \\
\text { Valordep } \\
\text { Post-hoc }\end{array}$ & $\begin{array}{l}1.15(1.88) \\
2.18(2.33) \\
3.29(1.90) \\
.002 \\
\mathrm{SI} \times \mathrm{S} 3 *\end{array}$ & $\begin{array}{l}2.08(1.84) \\
3.84(2.75) \\
5.47(3.52) \\
.000 \\
\mathrm{SI} \times \mathrm{S} 3 * \\
\mathrm{SI} \times \mathrm{S} 2 *\end{array}$ & $\begin{array}{c}4.26(4.64) \\
8.66(8.15) \\
7.47(4.03) \\
.013\end{array}$ \\
\hline
\end{tabular}

* Statistically significant correlation $(\mathrm{p}<0,05)$ - Test One-way ANOVA and Post-Hoc Bonferroni

* Statistically significant correlation $(\mathrm{p}<0,001)-$ Test One-way ANOVA and Post-Hoc Bonferroni

Subtitle: $\mathrm{n}=$ number of subjects; $\mathrm{A}=$ average; $\mathrm{sd}=$ standard deviation; $\mathrm{MSD}=$ moderate-severe disorder; $\mathrm{MMD}=$ mild-moderate disorder; $\mathrm{MD}=$ mild disorder; $\mathrm{F} 1=3$ years, 9 months through 5 years, 3 months; $\mathrm{F} 2=5$ years, 4 months through 6 years, 10 months; F3 $=6$ years, 11 months through 8 years, 5 months; NS1 $=5$ to 18 sessions; NS2 $=19$ to 36 sessions; and, NS3 $=$ more than 37 sessions.

The ABAB-Withdrawal and MultipleProbes, Maximal Oppositions, and Modified Cycles models have also been compared in previous studies with children who were speakers of Brazilian Portuguese(12,21-22) to identify the most efficient approach in the treatment of phonological disorders. Findings are unanimous in showing that these models lead to important therapeutic progress in children with phonological disorders. However, some studies have indicated that there are differences among the models with regard to the severity of phonological disorders. In the present study, we found fewer reductions in the number of altered distinctive features with the ABAB-Withdrawal and Multiple Probes model compared with the other approaches (Table 2). This could be explained by the fact that this model involves treating only 1 target sound at a time.
We found that all of the children experienced improvements in their speech, that is, their phonetic inventory included novel acquired sounds and their phonological system new phonemes, and the number of altered distinctive features also decreased after the intervention (Table 2). Other studies have reported similar findings relating to the treatment of children with phonological disorders (1-3,8,20-21,23).

We also observed a directly proportional relationship between the severity of the phonological disorder and the number of acquired sounds in the phonetic inventory and the number of phonemes in the phonological system. This means that the higher the severity (moderate-severe disorder), the greater the number of sounds in the phonetic 
inventory and the more phonemes in the phonological system (Table 2). These children also had more absent sounds than children with mild phonological disorders. This relationship has been previously observed and discussed in other studies(10,21-22).

The PCC-R used to classify the severity of phonological disorders is effective in differentiating children with and without phonological disorders(10). After phonological intervention, the PCC-R tends to increase and, consequently, there is a decrease of the severity of the phonological disorder. This demonstrates the acquisition of novel phonemes in the phonological system, and a decrease in the number of non-acquired phonemes (21-22). In this study all of the groups with different severities of phonological disorders showed novel phonetic acquisitions in their phonetic inventory and phonological system, which led to a decrease in the severity of the disorder and an increase in the PCC-R. There was also an accompanying reduction in the quantity of altered distinctive features $(5,20)$

In addition, the younger the child, the greater the increase in the number of sounds in the phonetic inventory and the greater the number of phonemes in the phonological system. This is because younger ( $<5$ years old) children had more absent sounds in the phonetic inventory or absent phonemes in the phonological system, which led to several substitutions and omissions of phonemes in speech. Correct production of consonants is more frequently observed in children older than 5 years compared with younger children (23). The PCC-R shows a significant and gradual increase with age $(10,24)$. The age of the children appears to be directly related to their speech performance (measured by the percentage of consonants correct). This performance is enhanced with increasing age due to neuromotor maturation, which is necessary for speech $(10,25)$. Children under 5 years have a greater chance of presenting with a speech disorder than those who are over 8 years due to a number of reasons, including maturation of metalinguistic functions (26).

The number of therapy sessions was also directly related to the acquisition of sounds/phonemes because the higher the number of sessions, the greater the number of sounds worked on and, consequently, acquired. The ABABWithdrawal and Multiple Probes, Maximal Oppositions, and Modified Cycles models all have a similar number of therapy sessions for children with phonological disorders (4).

The number of therapy sessions required for the treatment of phonological disorders still requires further investigation and clarification. A literature review (27) of the intensity, frequency, and duration of interventions found widely diverse data: treatment duration, 7 to 18 months; frequency, 2-3 times a week; session duration, 30-60 minutes. Much about these factors remains controversial and further clarification is required; for instance, would it be better to have 3 sessions a week for 6 weeks or 1 session a week for 24 weeks? Moreover, it is unclear what the ideal frequency of sessions is for a particular intervention (27). Further studies are required to elucidate these important components of phonological therapy.

\section{CONCLUSION}

Our findings indicate that there was a favorable evolution in the acquisition of sounds in the phonetic inventory and phonemes in the phonological system as well as a reduction in the number of altered distinctive features among all 3 therapeutic models regardless of the severity of the phonological disorder, age, or the number of sessions.

The therapeutic models compared-Modified Cycles, Maximal Oppositions, and ABAB - Withdrawal and Multiple Probes_-were all effective for the participants and there were no significant differences among them. It was verified that the lower the level of severity of the disorder, the greater the number of acquired sounds in the phonetic inventory and of phonemes in the phonological system, as well as the lower the number of altered distinctive features.

\section{REFERENCES}

1. Crosbie S, Holm A, Dodd B. Intervention for children with severe speech disorder: a comparison of two approaches. Int J Lang Commun Dis. 2005;40(4):467-91.

2.Pagliarin KC, Mota HB, Keske-Soares M. Análise da eficácia terapêutica em três modelos fonológicos de abordagem contrastiva. Pró-Fono. 2009;21(4):297-302.

3. Topbas S, ÜnalÖ. An alternating treatment comparison of minimal and maximal opposition sound selection in Turkish phonological disorders. Clin Linguist Phon. 2010;24(8):646-68.

4. Melo RM, Wiethan FM, Mota HB. Tempo médio para a alta fonoaudiológica a partir de três modelos com base fonológica. Rev CEFAC. 2012;14(2):243-8.

5. Ceron MI, Keske-Soares M. Análise do progresso terapêutico de crianças com desvio fonológico após aplicação do Modelo de Oposições Múltiplas. J Soc Bras Fonoaudiol. 2012;24(1):91-5. 
6. Pagliarin KC, Brancalioni AR, Keske-Soares M. Terapia fonológica a partir da estimulação de sons isolados e em conjunto. Rev CEFAC. 2012;17(1):23-7.

7. Gierut JA, Morrisette ML. Age of word acquisition effects in treatment of children with phonological delays. Appl Psycholinguistics. 2012;33:121-44.

8. Nunes DA, Payão LMC, Costa RCC. Desvio fonológicos na educação infantil. Rev CEFAC. 2010;12(2):331-6.

9. Gierut JA. Phonemic structures of delayed phonological systems. J Child Lang. 1994;21:291-316.

10. Castro MM, Wertzner HF. Estimulabilidade: medida auxiliar na identificação de dificuldade na produção dos sons. J Soc Bras Fonoaudiol. 2012;24(1):49-56.

11. Williams AL. Multiple oppositions: theoretical foundations for an alternative contrastive intervention approach. Am J Speech Lang Pathol. 2000;9(4):282-8.

12. Tyler AA, Figurski GR. Phonetic inventory changes after treating distinctions along an implicational hierarchy. Clin Linguist Phon. 1994;8:91-107.

13. Gierut JA. Maximal opposition approach to phonological treatment. J Speech Hear Dis. 1989;54:9-19. 14 Tyler AA, Edwards ML, Saxman JH. Clinical application of two phonological treatment procedures. J Speech Hear Dis. 1987;52:393-409.

15. Yavas M, Hernandorena CLM, Lamprecht RR. Avaliação fonológica da criança: reeducação e terapia. Porto Alegre: Artes Médicas; 1991.

16. Bernhardt B. Developmental implications of nonlinear phonological theory. Clin Linguist Phon. 1992;6(4):259-81.

17. Shriberg LD, Kwiatkowski J. Phonological disorders I: A diagnostic classification system. J Speech Hear Dis. 1982;47:226-41.

18. Mota HB. Aquisição segmental do português: um modelo implicacional de complexidade de traços [dissertation]. [Porto Alegre]: Faculdade de Letras,
Linguística Aplicada da Pontifícia Universidade Católica do Rio Grande do Sul; 1996.

19. Tyler AA. Commentary on "Treatment decisions for children with speech-sound disorders": revisiting the past in EBP. Lang Speech Hear Ser Schools. 2006;37:280-3.

20. Ceron MI, Keske-Soares M, Freitas GP, Gubiani MB. Mudanças fonológicas obtidas no tratamento de sujeitos comparando diferentes modelos de terapia. Pró-Fono. 2010;22(4):549-54.

21. Keske-Soares M, Brancalioni AR, Marini C, Pagliarin KC, Ceron MI. A eficácia da terapia para desvios fonológicos com diferentes modelos terapêticos. Pró-Fono. 2008;20(3):153-8.

22. Mota HB, Keske-Soares M, Bagetti T, Ceron MI, Melo Filha MG. Análise comparativa da eficiência de três diferentes modelos de terapia fonológica. Pró-Fono. 2007;19(1):6774 .

23. Gildersleeve-Neumann CE, Wright KL. English Speech Acquisition in 3- to 5-Year-Old Children Learning Russian and English. Lang speech Hear serv schools. 2010;41:42944.

24. Ferrante C, BorselJV, Pereira MMB. Aquisição fonológica de crianças de classe sócio econômica alta. Rev CEFAC. 2008;10(4):452-60.

25. Folha GA, Felício CM. Relações entre idade, porcentagem de consoantes corretas e velocidade de fala. Pró-Fono. 2009;21(1):39-44.

26. Goulart BNG, Chiari BM. Prevalência de desordens de fala em escolares e fatores associados. Rev. Saúde Pública. 2007;41(5):726-31.

27. Baker E, Williams AL. Intervention intensity for Speech Sound Disorders: How much and for how long? [Internet]. American Speech-Language-Hearing Association Convention, 2011 Nov 17-19; San Diego. [cited 2012 Jul 19]. Available form: http://search.asha.org/ default.aspx?q=elise $\% 20$ baker 